\section{Category}

Synthesis of Natural

Products and

Potential Drugs

\section{Key words}

\section{glecaprevir}

$\mathrm{S}_{\mathrm{N}} \mathrm{Ar}$ reaction

intramolecular

nucleophilic

substitution

macrocyclization

cycloetherification

R. D. CINK* ET AL. (ABBVIE INC., NORTH CHICAGO, USA)

Development of a Large-Scale Route to Glecaprevir: Synthesis of the Macrocycle via Intramolecular Etherification Org. Process Res. Dev. 2020, 24, 1373-1392, DOI: 10.1021/acs.oprd.0c00244.

\title{
Synthesis of Glecaprevir. Part 1
}

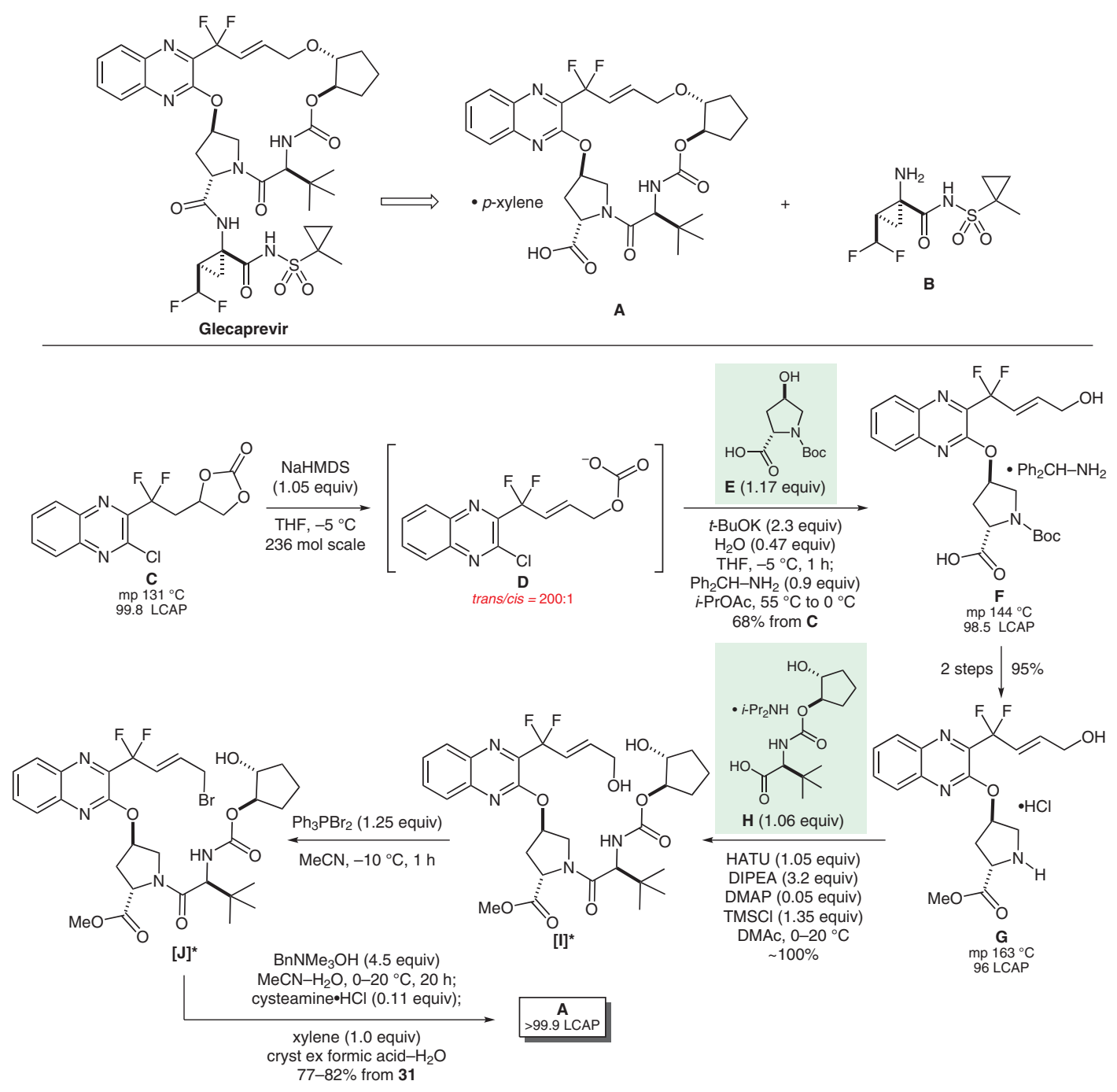

Significance: The combination of glecaprevir and pibrentasvir was approved in 2017 for the treatment of chronic hepatitis $C$ virus infections. A new large-scale synthesis of glecaprevir is described in two parts. Part 1 shown here concerns the construction of the 18-membered macrocycle A featuring as the key step an intramolecular cycloetherification of allylic bromide J. For part 2, see Org. Process Res. Dev. 2020 24, 1393; Synfacts 2020, 16, 1259.
Comment: The identification of solvates with low solubility allowed the crystallization of macrocycle $\mathbf{A}$ in high purity directly from the reaction mixture. The overall yield to macrocycle $A$ was $20 \%$ for the lowest yielding sequence through carbamate $\mathbf{H}, \mathbf{a}$ significant improvement on the 15\% yield of the enabling route based on ring-closing metathesis (Org. Process Res. Dev. 2020, 24, 183). 